\title{
Predicting Overwintering of Wheat Stripe Rust in Central and Northwestern China
}

\author{
Xiaoping Hu, ${ }^{1, \dagger}$ Shiqin Cao, ${ }^{2}$ Alex Cornelius, ${ }^{3}$ and Xiangming $\mathrm{Xu}^{4}$ \\ ${ }^{1}$ State Key Laboratory of Crop Stress Biology for Arid Areas and Key Laboratory of Integrated Pest Management on Crops in \\ Northwestern Loess Plateau, Ministry of Agriculture, and College of Plant Protection, Northwest A\&F University, Yangling \\ 712100, China \\ ${ }^{2}$ Institute of Plant Protection, Gansu Academy of Agricultural Science, Lanzhou 730070, China \\ ${ }^{3}$ Assimila Ltd., Reading, U.K. \\ ${ }^{4}$ Pest and Pathogen Ecology, NIAB EMR, East Malling, West Malling, Kent ME19 6BJ, U.K.
}

\begin{abstract}
Stripe rust, caused by Puccinia striiformis Westend. f. sp. tritici Erikss. (Pst), is an important disease of wheat. In China, Pst management has focused on the Gansu region where the pathogen can complete its annual cycle, including oversummering and overwintering. From this region, Pst inoculum is dispersed to the southern Yangtze River region in the late autumn/early winter and then to the main wheat production regions in the following spring. We used historical weather data (1995 to 2016) and field stripe rust assessment data ( 8 years) in the spring to evaluate the performance of a published model for predicting the potential of Pst overwintering in the Gansu region. Both predicted and observed values of

rust overwintering for disease management. The model predictions fitted with observed values satisfactorily. All high incidences of rust in the spring were observed in the fields of the monitoring sites where the high potential of overwintering was predicted. Conversely, the predicted rust overwintering potential was also close to zero in the fields where rust was not observed in the spring. There were many false-positive predictions, which may be attributable to the absence of rust in autumn seedlings. This model can be used to target rust management in the spring and its effectiveness will be further improved if autumn rust assessment can be carried out.
\end{abstract} rust overwintering in the Gansu region varied greatly between years and between sites within a single year, indicating the value of predicting
Keywords: cereals and grains, epidemiology, field crops, fungi
Stripe rust, caused by Puccinia striiformis Westend. f. sp. tritici Erikss. (Pst), is an important disease of wheat worldwide (Chen 2005). Stripe rust is a polycyclic disease, and Pst can produce urediniospores in multiple cycles in a crop season when climatic conditions favor disease development. The annual cycle of stripe rust on winter wheat in China can be divided into four stages: oversummering, infection of seedlings in autumn, overwintering, and spring epidemic. The disease must overcome the two bottlenecks of overwintering and oversummering in living green wheat plants to complete its life cycle (Li and Zeng 2002; Sharp and Hehn 1963). Temperature is the most important factor determining both Pst overwintering and oversummering potential on wheat. In most wheat growing areas in China, the pathogen usually cannot survive annually because of the temperature limits on its overwintering and oversummering.

In China, stripe rust oversummers primarily in the mountainous regions of southern and eastern Gansu Province and northwestern Sichuan Province for three major reasons: relative low temperature, variable harvest time at different altitudes, and volunteer wheat seedlings following harvest in the summer. Thus, Pst can survive and reinfect volunteer wheat seedlings in the summer. Furthermore, winter wheat is sown early in the regions, allowing Pst from volunteer plants to infect autumn seedlings. Spores produced from the

${ }^{\dagger}$ Corresponding author: X. Hu; xphu@nwsuaf.edu.cn

Funding: This work was supported by grants from the National Key Research and Development Program of China (2018YFD0200402), the National Key Basic Research Program of China (2013CB127700), the National Natural Science Foundation of China (31071640 and 31271985), and the U.K. Science Technology Facility Council-funded U.K.-China Newton project (ST/ N006852/1)

The author(s) declare no conflict of interest.

Accepted for publication 7 August 2019.

(C) 2020 The American Phytopathological Society oversummering region are dispersed (usually via air current) eastward to cause infections on winter wheat seedlings in the late autumn in more easterly regions. Similarly, Pst spores from the volunteering plants and autumn seedlings are dispersed to cause infections on winter wheat in the south Yangtze River region. Because of the relatively warm winter temperature in the Yangtze River region, stripe rust can infect, colonize leaves, and sporulate during the winter. In the coming spring, spores from the Yangtze River region are dispersed with air current toward the northeast direction into the main wheat production area in central China, resulting in crop losses. Thus, managing stripe rust in the oversummering region in the spring is critically important in China in order to reduce disease pressure in the main wheat production area the following year.

The spring epidemic severity of stripe rust in the oversummering area is primarily dependent on the following factors: cultivar susceptibility, autumn rust infection severity, extent of rust overwintering, and spring climatic conditions. The ability to predict pathogen survival potential may enable timely implementation of integrated disease management strategies to reduce the inoculum source and prevent the formation of disease foci in the spring. Warm winters favor Pst survival in infected leaves, whereas severe winters do not allow the pathogen's survival (Grabow et al. 2016). Potential Pst overwintering areas in China have been identified (Chen et al. 2013; Ma et al. 2005; Shen and Wang 1962) based on data from field observations. However, recent field observations suggest that the overwintering boundary may have been gradually pushed toward the northwest (Pan et al. 2011; Yao et al. 2014), which may partially result from climate changes (Fang et al. 2012). In addition to low temperatures, wind chill may also result in reduced $P$ st overwintering potential (Ma et al. 2016). In cold high-altitude regions, Pst is likely to overwinter in young green leaves as a latent infection established in late autumn (Ma et al. 2016). Pst mycelia inside green leaves may be killed by low temperatures rather than through the death of green leaves (Ma et al. 2015).

Many models have been developed to describe the relationship between winter temperature and stripe rust epidemics based on field observations (Coakley and Line 1981; Coakley et al. 1982, 1988) and were further revised (Sharma-Poudyal and Chen 2011). We used 
field-collected data in northwestern China to develop a quantitative model that predicts the overwintering potential of stripe rust on winter wheat (Xu et al. 2019). Overwintering potential is predicted based on the number of days with a daily average temperature below -2 and $-4^{\circ} \mathrm{C}$ for cultivars with weak and strong winter hardiness, respectively.

In this study, we used this model to predict the overwintering potential of stripe rust on wheat in four provinces located in central and northwestern China, including Gansu, a key region of stripe rust epidemiology in China. Weather data recorded at 340 stations in the four provinces from 1995 to 2017 were used to predict rust overwintering potential. Furthermore, the predicted overwintering potential was compared with the observed rust occurrence in the spring at the monitoring sites in Gansu Province. Because the rust survey in the spring was only for disease management, the number and exact locations of sites surveyed varied greatly among years. Nevertheless,
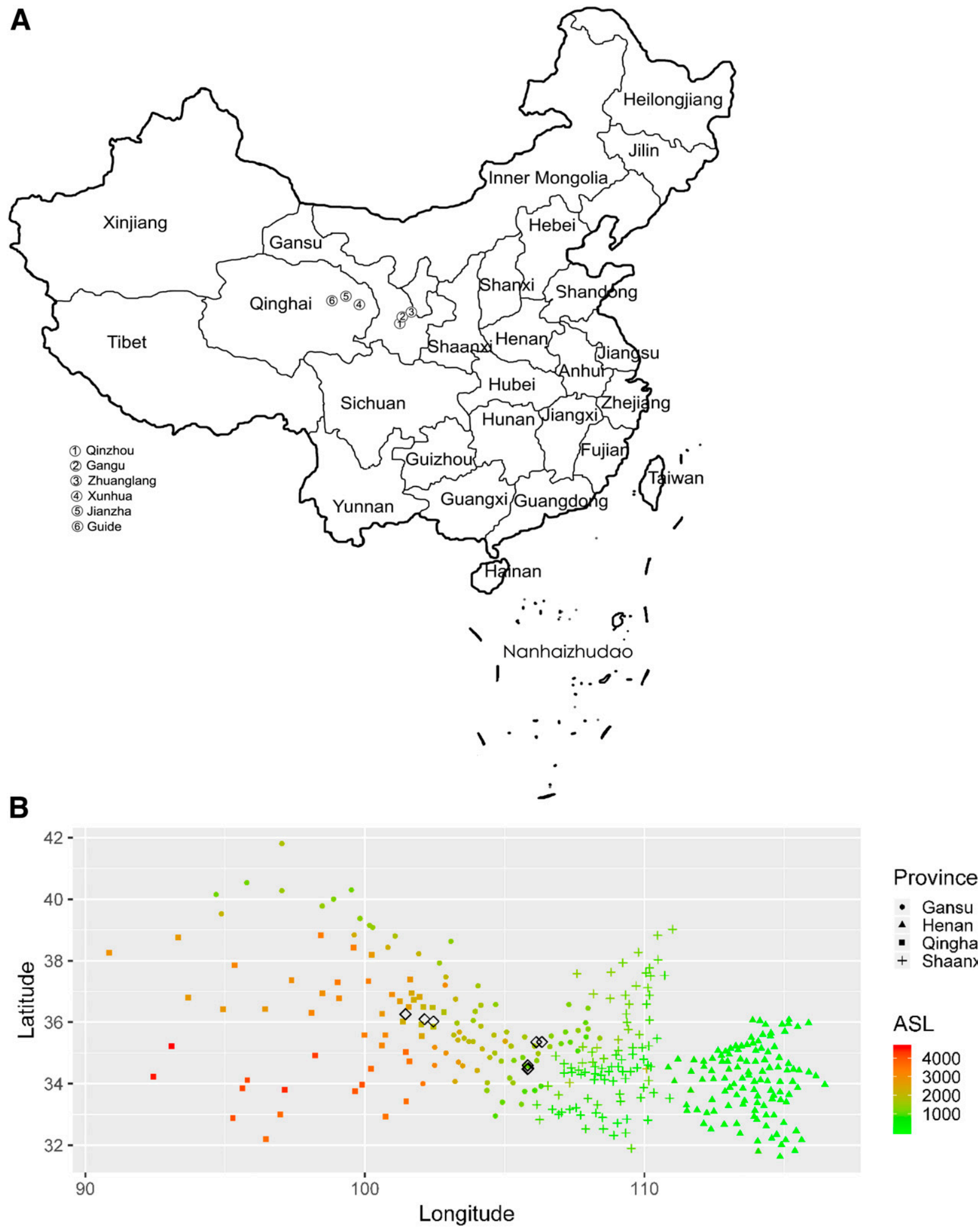

Fig. 1. A, The location of the four provinces in China. B, Latitude and longitude of all weather loggers in the four provinces from which daily average temperature data were used in this study. The circles with numbers in (A) and open diamonds with a black edge in (B) indicate the sites where the experimental data were collected to develop a model predicting the overwintering potential of wheat stripe rust (Xu et al. 2019). ASL = above sea level in meters. 
this is the best long-term data set we currently have on the extent of spring rust development in Gansu.

\section{Materials and Methods}

Temperature data. Daily average temperatures from 1 January 1995 to 31 October 2017 were obtained from 340 weather stations located in four Chinese neighboring provinces (Fig. 1), including Gansu where rust overwintering and early spring epidemic development is of great significance for disease management in China. These data passed the quality control procedure as implemented by the Chinese Meteorological Office. The density of these weather stations varied greatly within regions (Fig. 1) and was much denser in the eastern part than in the western part in China because of differences in the terrain and local population. There were 116, 95, 80, and 49 weather stations in Henan, Shaanxi, Gansu, and Qinghai provinces, respectively. The highest and lowest locations were 4,612.0 and $32.5 \mathrm{~m}$ above sea level, respectively.

Predicting rust overwintering. A recently published model was used to predict the overwintering potential of strong winter hardiness cultivars. This model was derived from field data collected in 2012 to 2014 in northwestern China (Qinghai and Gansu provinces, Fig. 1) (Xu et al. 2019). The model is as follows:

$$
\ln \left(\frac{p}{1-p}\right)=-1.411-0.039 \bullet \text { DLT4 }
$$

where $p$ is the probability of the rust pathogen being able to overwinter and DLT4 is the number of days with daily average temperatures below $-4^{\circ} \mathrm{C}$ during the 30 days from 30 December to 28 January the following year. This model did not include low temperatures outside this period during the winter because there were only a few extra days with an average temperature below $-4^{\circ} \mathrm{C}$ for one season at a few sites during the study period for model development (Xu et al. 2019). This model has maximum and minimum predictions of overwintering potential of 0.20 (DLT4 = 0) and 0.07 (DLT4 = 30), respectively. In this study, all of the estimated overwintering values were normalized to the range of 0 to 1 .

Temporal trends in winter temperature. For each winter, the average temperature from 16 December to 15 March the following year was calculated for each logger location to represent the overall winter temperature. Similarly, the number of days with an average temperature below $-4^{\circ} \mathrm{C}$ was calculated over the same period for each location. Then, for every logger location, a simple linear regression model was fitted to determine whether there was a linear trend in the average temperature or the number of days with temperatures below $-4^{\circ} \mathrm{C}$ during the 22-year period. Similarly, a linear model was fitted to the predicted annual rust wintering potential over time for each location.

Spring rust assessment in Gansu. In Gansu Province where Pst is able to oversummer, a number of sites were assessed for the incidence of rust in April to measure overwintering potential and early spring epidemics for disease management. The survey results were then used by the local government to finalize and implement rust management strategies across a number of provinces in China. In

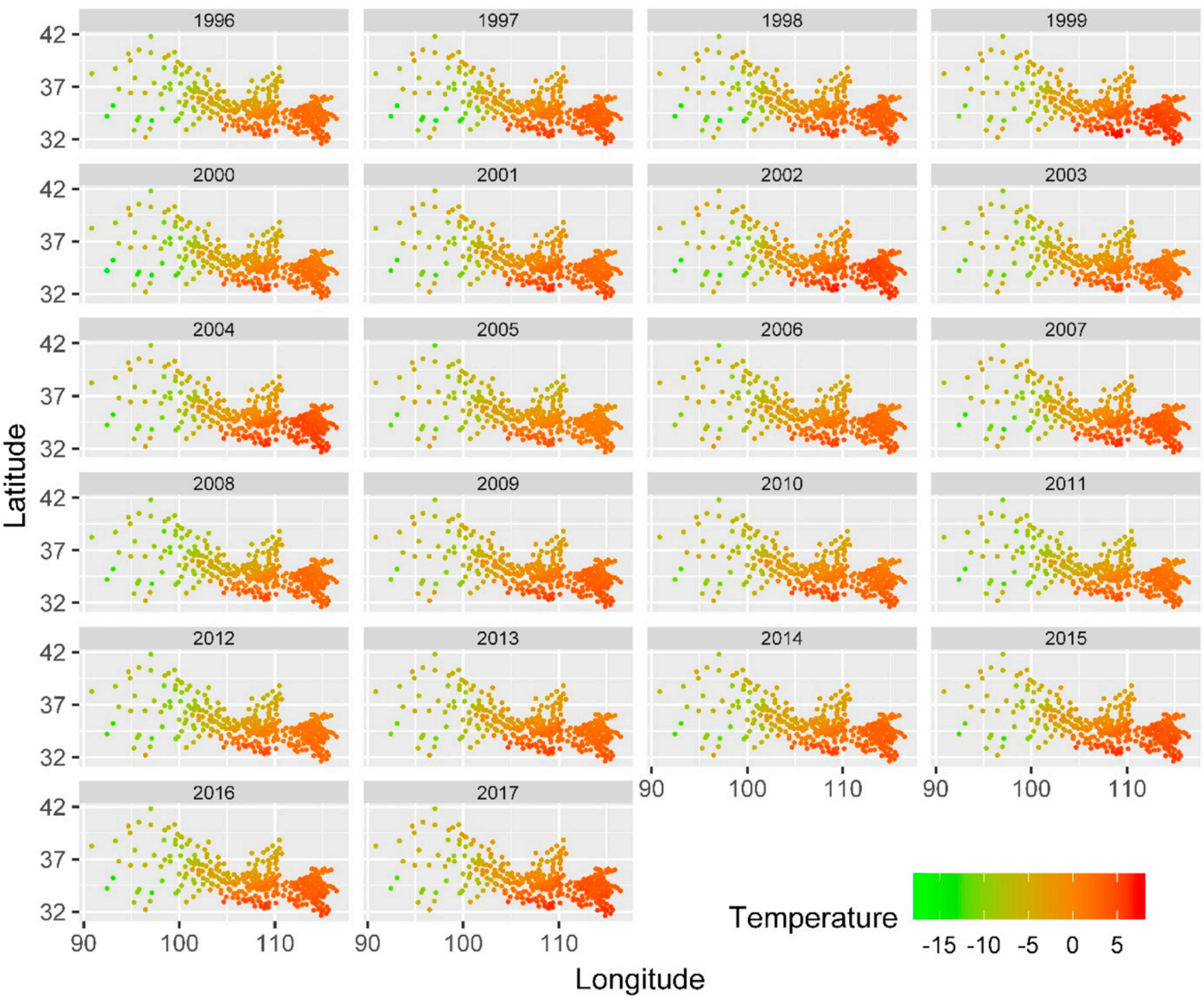

Fig. 2. Average winter temperature for each logger site from 16 December to 15 March the following year in the four provinces in China from winter 1995/1996 to winter 2016/2017. 
total, 425 sites were assessed for rust in the spring of 8 years in Gansu. There were 69, 97, 37, 81, 46, 43, 21, and 31 sites assessed in 2005, 2007, 2008, 2009, 2011, 2012, 2014, and 2015, respectively. Within each site (usually an individual local village), a number of fields were selected for rust assessment, with the size of the individual fields usually in the range of 70 to $700 \mathrm{~m}^{2}$. In total, 2,117 fields (approximately five fields per site) were assessed in the 8 years. Spring assessment was carried out in 2013 but failed to find any rust lesions.

Depending on the field size and the overall level of stripe rust and the field, rust was assessed through one of the two following methods. First, fields with a very low incidence of rust were examined. Within a field with a size $>667 \mathrm{~m}^{2}$, five areas (each approximately $70 \mathrm{~m}^{2}$ ) were selected to examine stripe rust symptoms. For a field with a size $<667 \mathrm{~m}^{2}$, the whole field was assessed for stripe rust. Within each selected area or whole field, an assessor walked slowly and regularly squatted down to check for rust symptoms. Second, fields with a moderate or high incidence of rust were examined. Five areas (each approximately $2 \mathrm{~m}^{2}$ ) were randomly selected; 200 leaves within each area were examined for rust symptoms.

Incidences of leaves, areas, and fields with stripe rust lesions were estimated for each location. Plants in 1,154 of the 2,117 fields were examined just prior to or at the elongation stage, 605 fields were examined at the preanthesis stage, and the remaining fields were examined at the period from anthesis to the milky stage.

\section{Results}

Temperature over time. Figure 2 shows the average annual winter temperature for 22 years at each location where a weather station was located in the four provinces. As expected, Qinghai and Henan were the coldest and warmest provinces in winter, respectively (Figs. 2 and $3 \mathrm{~A}$ ). For instance, the average annual winter temperature ranged from -9.5 to $-6.5^{\circ} \mathrm{C}$ and from 0.5 to $5.2^{\circ} \mathrm{C}$ for Qinghai and Henan provinces, respectively. Similarly, Qinghai had more days of DLT4 than the other three provinces (Figs. 3B and 4). Among the four provinces, Gansu had the greatest variation of DLT4 in the winter ( 25 to 51 days), whereas Henan had the least variation of DLT4 (0 to 9 days) from 1995 to 2017.

For most locations, average annual winter temperatures did not show an apparent increasing trend over the 22-year period (Fig. 5).
However, the annual winter temperature increased significantly at 15 sites during the 22-year period, with an average increase of $0.1^{\circ} \mathrm{C}$ per year. Fourteen of the 15 sites were in Qinghai Province and the other site was in Gansu Province (Figs. 1 and 5). These 15 sites were all located at high altitudes $(>3,000 \mathrm{~m})$.

Rust overwintering predictions. Winter temperature was not a limiting factor for rust overwintering in Henan and southern Shaanxi (Fig. 6) because DLT4 values were all within the range of 0 to 10 days (Fig. 4). The average predicted overwintering potential was 0.91, 0.66, 0.30, and 0.04 for Henan, Shanxi, Gansu and Qinghai, respectively. For most sites in Qinghai and northwest Gansu, the predicted Pst overwintering potential was close to zero. In addition to the large variation in the predicted overwintering potential among locations, there were large fluctuations in the average overwintering potential among years, particularly in Gansu and Shaanxi (Figs. 3C and 6). However, despite the large variability among sites in Shaanxi and Gansu, Pst overwintering was possible for most sites; this was particularly so in warm years, such as 2002 and 2010 (Fig. 6).

Observed rust overwintering in Gansu. Of the 425 sites, there were 258 sites with no rust detected in the early spring, 83 sites with stripe rust incidence $\leq 1 \%, 12$ sites with an incidence from $>1$ to $\leq 3 \%$, and 72 sites with an incidence $>3 \%$. Rust incidence had large variation among individual fields in spring, and the incidence could be $>50 \%$ in some fields.

Apart from 2013, a varying degree of rust lesions was observed in all of the other years. In spring 2013, there was a severe drought event, causing wheat to not grow well; of course, another contributing factor was that the autumn epidemics in 2012 may not have been severe. In addition to 2013, spring rust was low in all years except 2005, 2014, and 2015 (Fig. 7). In 6 years, Pst lesions were not seen in $>50 \%$ of the locations assessed in the spring. The incidence of locations with spring Pst lesions ranged from 25 (2009) to 77\% (2005). The incidence of leaves with rust lesions in the spring was $>3 \%$ for nearly half and one-third of the locations in 2005 and 2014, respectively (Fig. 7). Within individual years, the level of spring rust also varied greatly among sites; many sites had a very low level of rust leaf incidence $(<1 \%)$ (Fig. 7).

Rust incidence was generally higher on plants at late developmental stages than at early stages. For instance, only 11 of the 245 sites
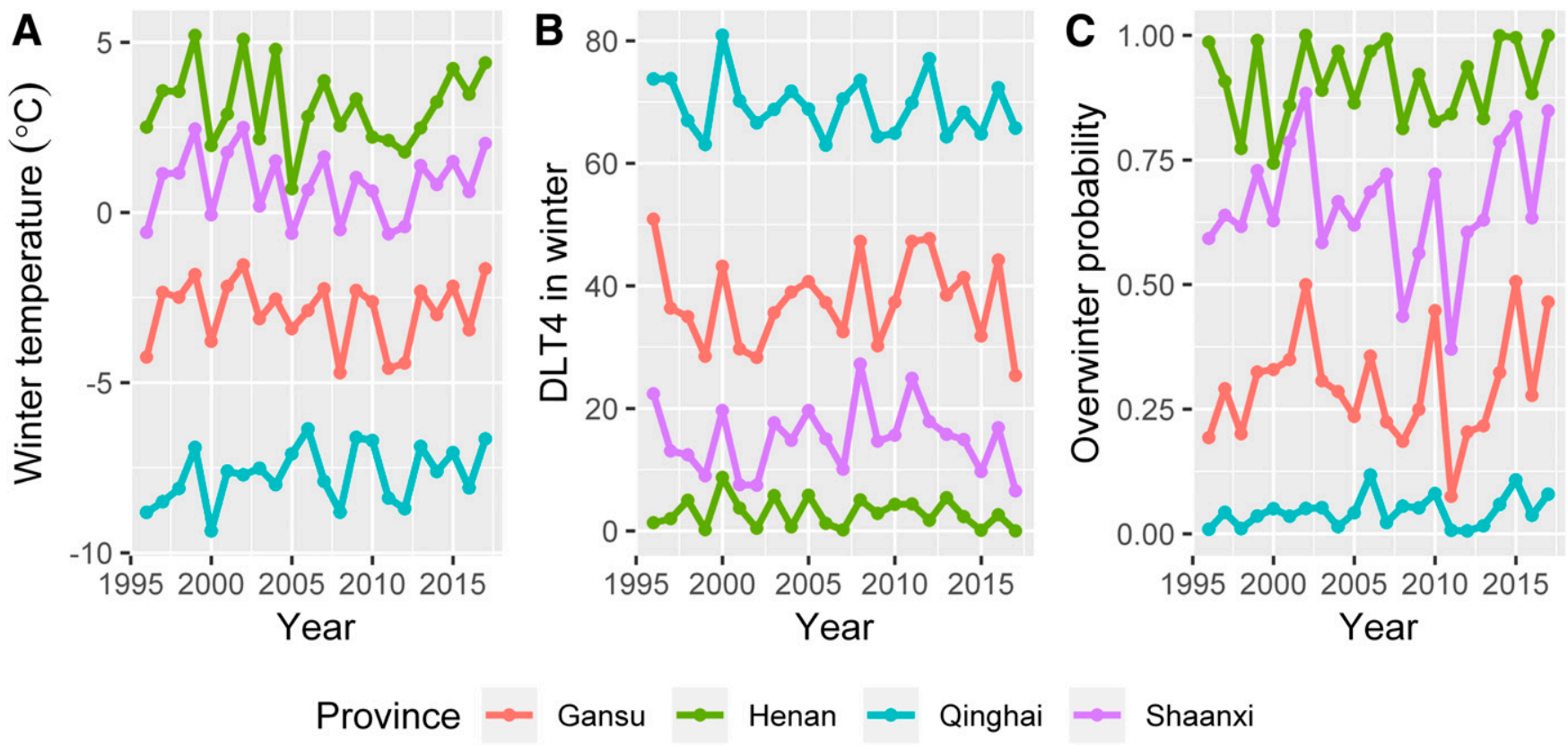

Fig. 3. Temporal plots of $\mathbf{A}$, average winter temperature, $\mathbf{B}$, average number of days with daily average temperature below $-4^{\circ} \mathrm{C}$ in the winter (DLT4), and $\mathbf{C}$, average probability values of wheat stripe rust overwintering on cultivars with strong winter hardiness in each province. A winter period is defined from 16 December to 15 March the following year. Rust overwintering potential was estimated from a previously published model (Xu et al. 2019). 


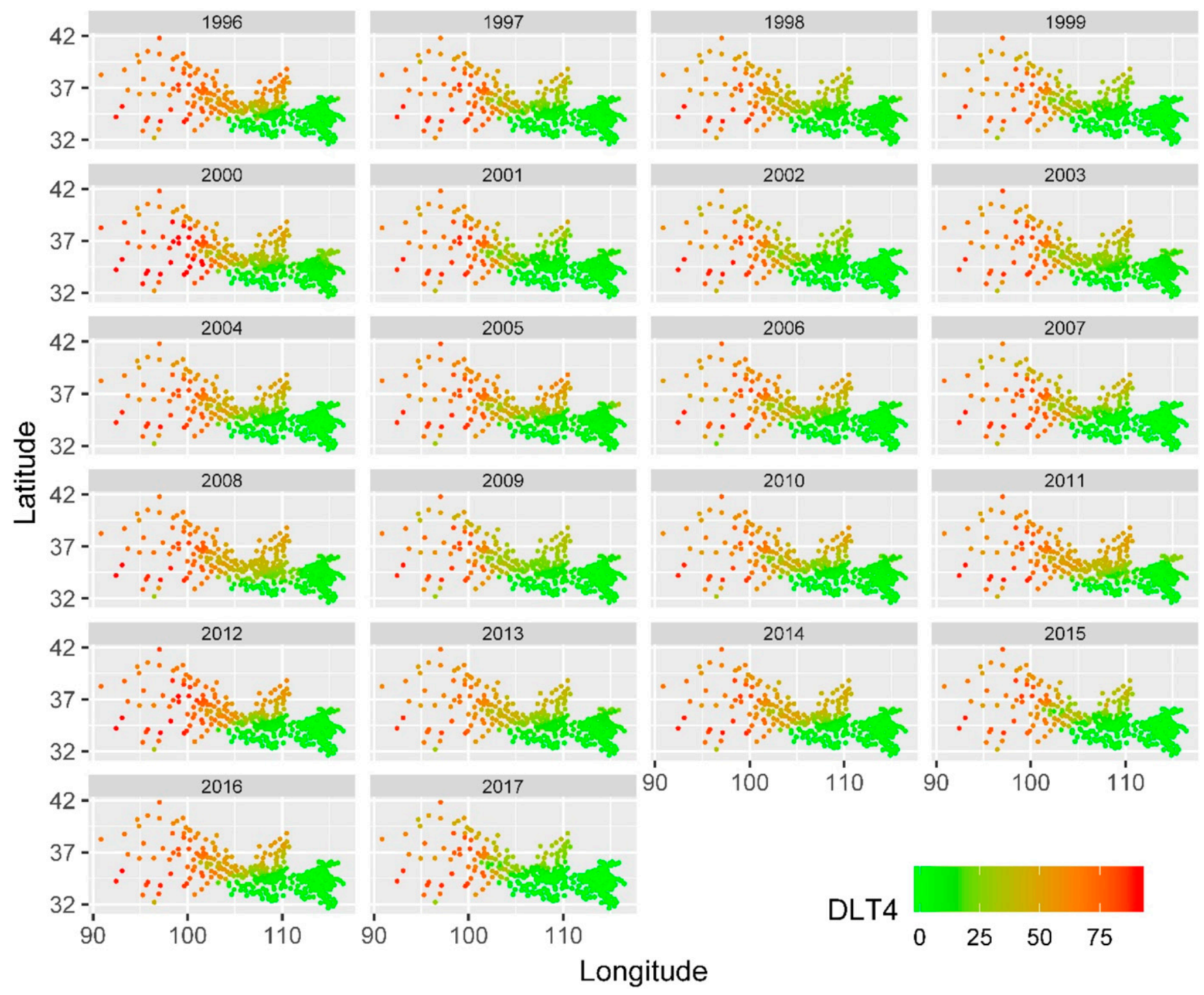

Fig. 4. Number of days with average daily temperature below $-4^{\circ} \mathrm{C}$ during the entire winter period (DLT4; 16 December to 15 March the following year) for each logger site for all 22 winters. This specific variable was used to predict the overwintering potential of wheat stripe rust.

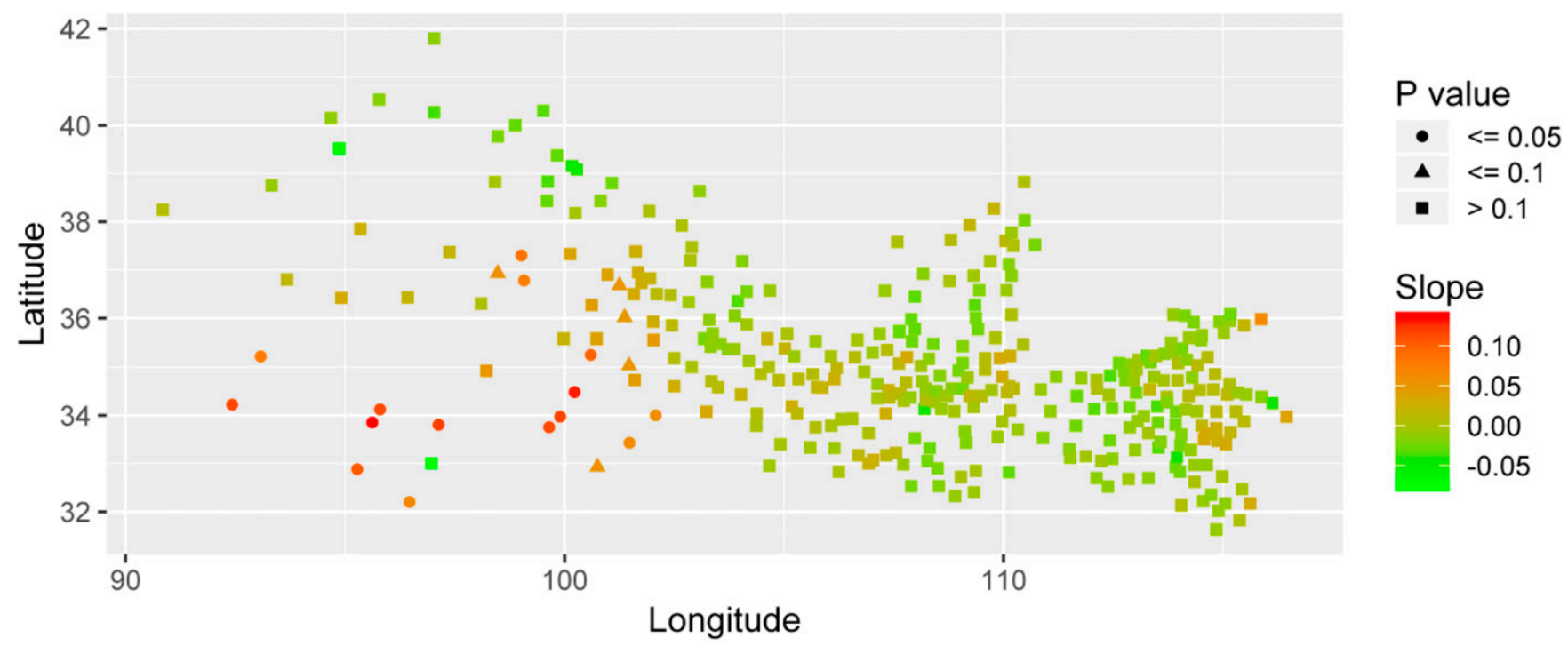

Fig. 5. The overall linear change rate (slope) in the average winter temperature from 16 December to 15 March the following year for each logger site during the period from winter 1995/1996 to winter 2016/2017. The color indicates the magnitude of this annual change rate, whereas the symbol shape indicates its statistical significance. 


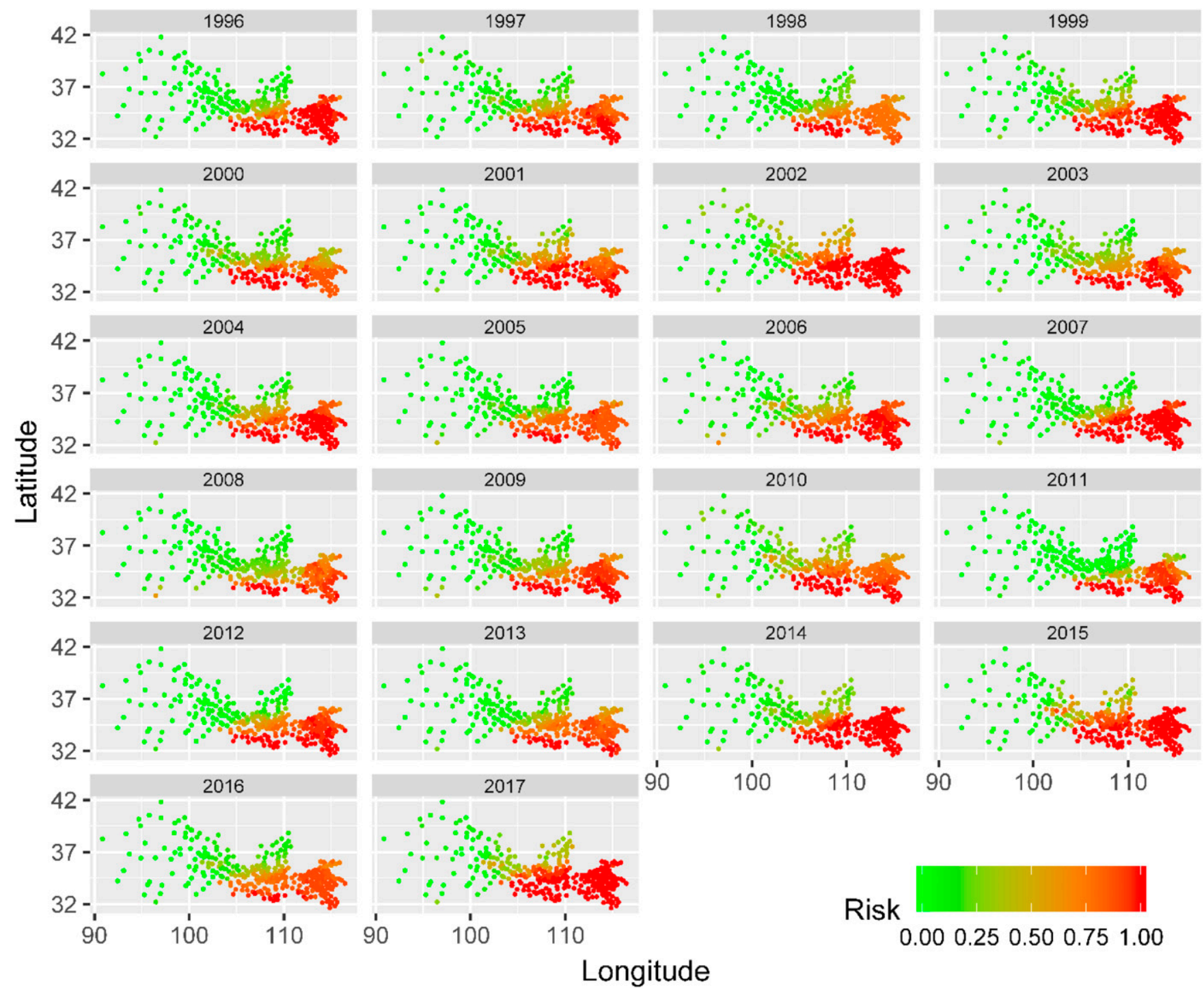

Fig. 6. Predicted overwintering potential of wheat stripe rust on cultivars with strong winter hardiness based on a previously published model (Xu et al. 2019). The actual predictions were normalized taking into account the background information of the data from which the model was developed, as described in the main text.

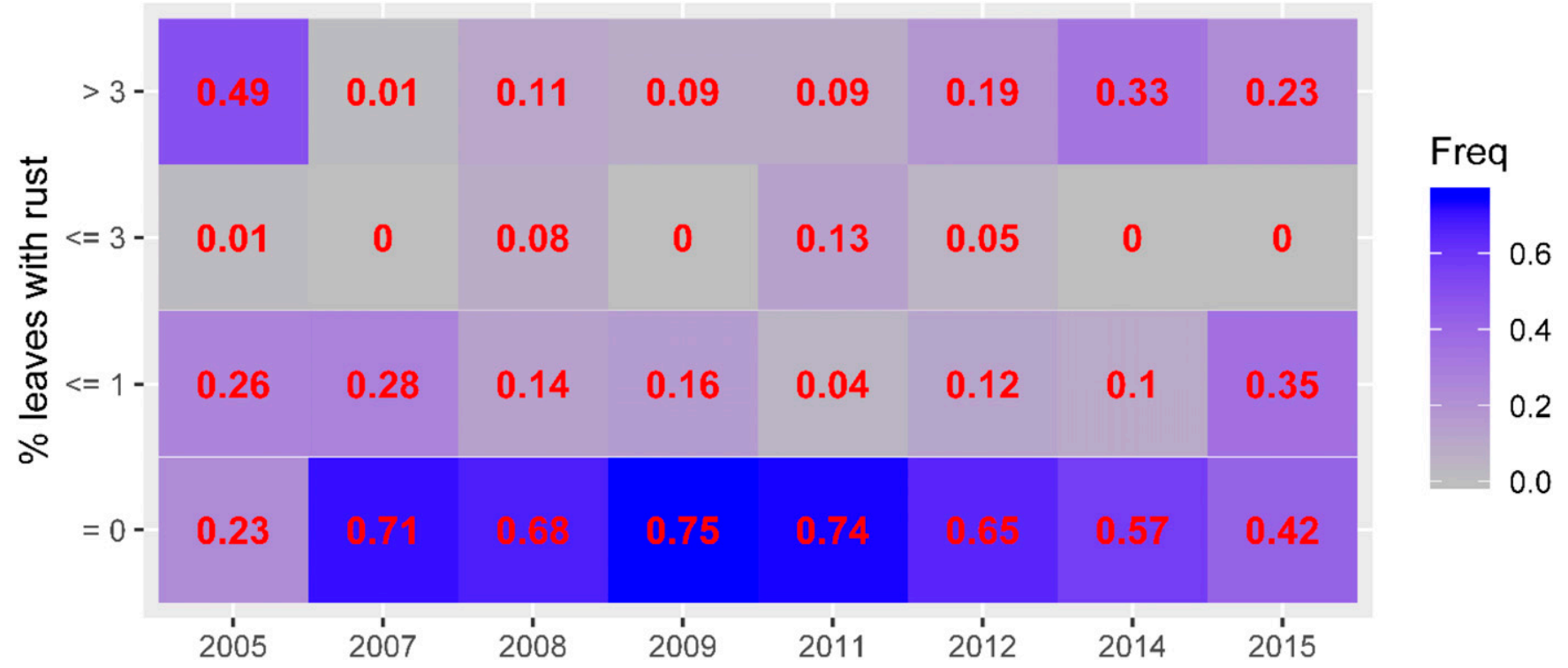

Fig. 7. Proportion of sampled sites with different levels of rust incidence on leaves when assessed in the spring. Rust was assessed in 425 sites (consisting of 2,117 individual fields) in the spring over the 8 years. 
where plants were either prior to or at the elongation stage at the time of assessment had a rust leaf incidence $>3 \%$, compared with 61 of 180 sites with plants past the elongation stage. This difference was highly significant $(P<0.001)$.

Comparison of predicted with observed rust in Gansu. Figure 8 shows the observed rust in the spring and the predicted probability of overwintering. Over the 8 years, predicted overwintering potential was higher in 2014 and 2015 winters than in other winters (Figs. $3 \mathrm{C}$ and 8 ). The predicted rust overwintering varied greatly among locations within each year, as did the observed spring rust. Despite the large variation in the number of sites assessed, their geographical locations, and the levels of rust observed, Figure 8 shows the following results. First, a high level of spring rust occurred only in southern locations. Second, the high level of spring rust was observed only for those sites in the regions with high predicted overwintering potential (usually $>0.50$ ), as shown for 2005, 2014, and 2015. Third, spring rust was not observed for those sites in the regions with very low predicted overwintering potential (usually $<0.25$ ). This was best illustrated by the data from 2007, 2009, 2011, and 2012, in which locations were more spread out geographically. Finally, spring rust was not observed for many sites in the regions with moderate to high values of predicted overwintering potential in all years, indicating a high level of false-positive predictions.

\section{Discussion}

Wheat stripe rust overwintering is important in the northwest regions of China, particularly in Gansu Province, which is the only region where the rust can complete its annual disease cycle (Chen et al. 2013). Thus, despite wheat being a minor crop in Gansu, rust development in the region may have a disproportionate effect on crop losses in the main wheat production area in China, as the Gansu region provides the initial rust inoculum in autumn/early winter to winter wheat in the Yangtze River region, which in turn provides rust inoculum to the main wheat production area in the following spring. Accurate prediction of overwintering hot spots in Gansu will allow timely implementation of control measures in the early spring to control rust and hence significantly reduce the oversummering inoculum, which leads to the autumn epidemic in the region. In this study, we evaluated a recently developed model (Xu et al. 2019) for predicting stripe rust overwintering in Gansu.

Both model-predicted rust overwintering potential and observed rust in the spring in the Gansu region showed a large variability

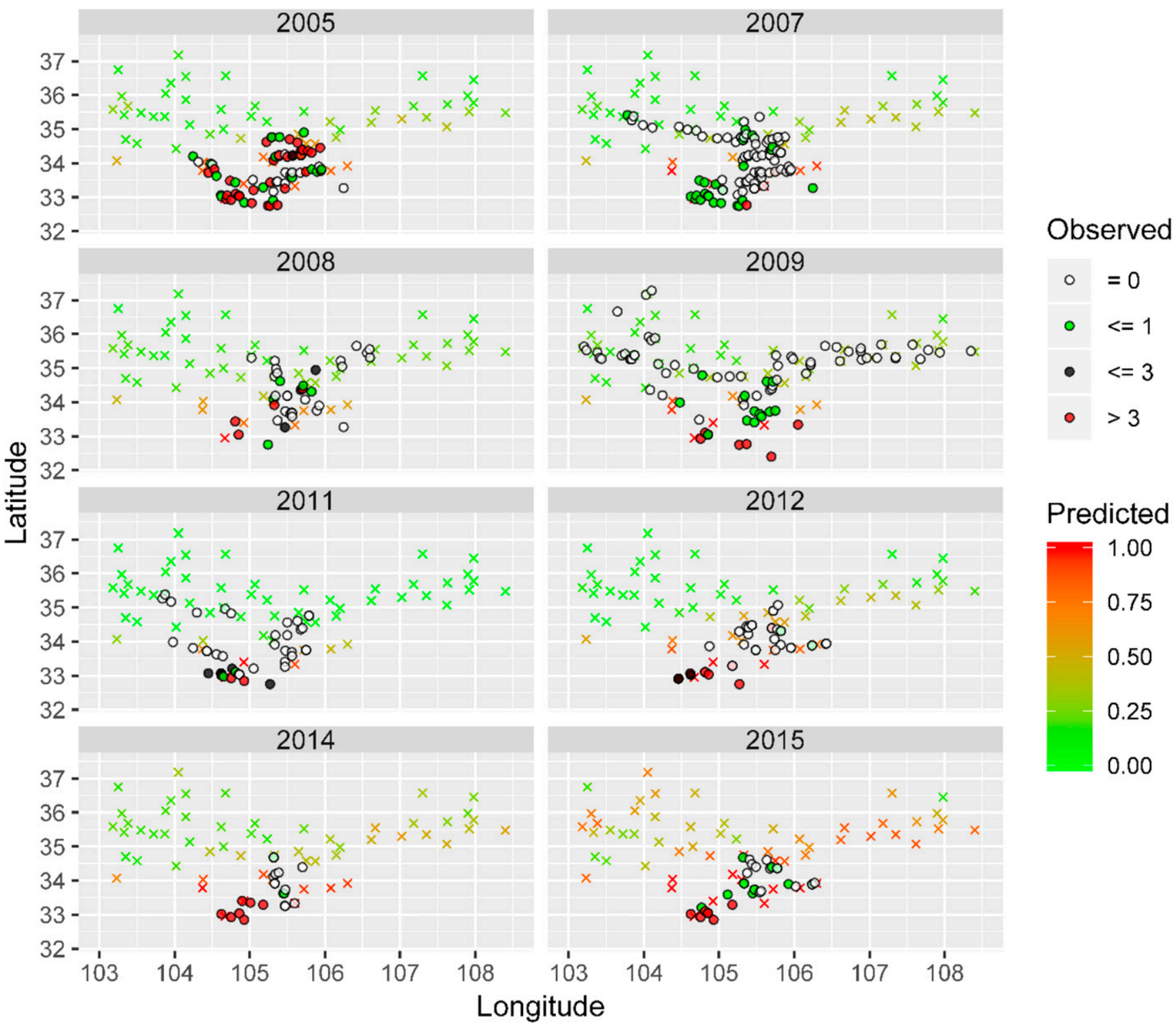

Fig. 8. Predicated rust overwintering potential (cross symbols) based on a previously published model (Xu et al. 2019) for the Gansu Province, plotted together with observed incidences of leaves with rust (circles) in the spring. Rust was assessed in 425 sites (consisting of 2,117 individual fields) in the spring of 8 years. In addition, no rust was observed in the spring 2013. 
between years and between sites within a single year. This variability indicated the need for predicting rust overwintering in order to apply more targeted disease management in the spring. Furthermore, these results are encouraging, showing that the model is able to predict the overwintering potential of rust in Gansu. Thus, the high incidence of rust in the spring occurred only in the regions where high overwintering potential was predicted. Conversely, rust in the spring was not observed in the regions where the predicted rust overwintering potential was close to zero.

There were many false-positive predictions; namely, high rust overwintering potential was predicted but no rust was observed in the spring. This false-positive prediction was expected, since the present model is only based on the winter temperature. In addition to weather conditions, two other important factors affecting spring rust severity are cultivar resistance and autumn rust severity on seedlings. We argue that autumn rust severity is primarily responsible for these false-positive predictions. First, wheat in the study region is usually grown by small-scale growers who select cultivars based on yield potential rather than rust susceptibility. Second, there are many rust races present in the study region, regarded as the $P$ st diversity center in China; thus, it is unlikely that most cultivars grown in the region could be resistant against the range of races present.

In this study, we did not assess the stripe rust severity in autumn seedlings in each field. Ideally, to validate the model, it would be better to assess both autumn and spring rust severities at the same locations in order to estimate rust overwintering accurately. Indeed, it would be even better to tag plants with rust lesions in the autumn and then assess rust development on these tagged plants in the spring. This is the approach we used to obtain experimental data to develop the overwintering model evaluated in this study (Ma et al. 2016; Xu et al. 2019). Unfortunately, it would be cost prohibitive to obtain a sufficient amount of data for model validation using this approach, given the number of sites needed and geographical distances among sites. Thus, we used historical data for the purpose of model validation. When implementing the model in practical disease management, we may use remote sensing technology to assess rust severity in late autumn. For instance, we demonstrated that it is possible to estimate wheat stripe rust development with unmanned aerial vehicle (UAV)based imaging technology (Su et al. 2018). By combining the model prediction with autumn rust assessment, spring rust management can be further prioritized with confidence. This kind of disease management can be implemented in the Gansu region, since the local government is responsible for providing small-scale growers with information and advice.

There was no overall trend in predicted rust overwintering potential in the four provinces over the 22-year period, although there were large variations among years. However, there is a clear indication of increasing winter temperature over time in the Tibetan Plateau at an approximate annual rate of $0.1^{\circ} \mathrm{C}$. Indeed, such an increase in temperature has already been reflected in the cropping system in the regions (Liu et al. 2017). Nevertheless, this increase in temperature has not yet affected rust overwintering, since the rust overwintering model is based on the number of days with daily average temperatures below $-4^{\circ} \mathrm{C}$ rather than the exact temperature.

In validating the model, we had to normalize the predicted values to the range of 0 to 1 . This is necessary because the data used to develop the model were collected at the sites where the DLT4 values were all $<30$ days. Thus, the model predicted a minimum overwintering potential of approximately 0.2 . However, in the present data set, there are many year-site combinations with a DLT4 much $>30$ days. Consequently, using the model to predict overwintering potential without normalization would lead to overestimation of overwintering potential for those sites with a DLT4 much $>30$. Of course, normalizing the model predictions may lead to underestimation of overwintering for those sites with a DLT4 just over 30 days; this occurred only for a limited number of cases. Another aspect that the present model did not include is the winter snow cover, which could reduce the negative effect of cold temperature on rust survival (SharmaPoudyal et al. 2014). We did not include this factor in the model for two reasons. First, we did not have sufficient data to predict the quantitative effects of snow cover (and its duration) on rust overwintering. In addition, it would be even more challenging to obtain snow cover (and duration) data for use in the model in practice. The model may be further improved by incorporating other climatic variables that may affect Pst overwintering, such as dew point temperature, snow cover, relative humidity, and precipitation (Sharma-Poudyal et al. 2014).

In summary, this simple model satisfactorily predicted rust overwintering potential in the Gansu region; all of the locations with spring rust lesions observed were in regions with high predicted values of overwintering potential. The impact of false-positive predictions in practical disease management can be minimized if model predictions are combined with autumn rust severities. Currently, we are developing strategies of using an UAV-based imaging system (Su et al. 2018) to assess autumn rust in winter wheat and are evaluating the combined use of autumn rust assessment and overwintering predictions for rust management in the spring.

\section{Literature Cited}

Chen, W., Kang, Z., Ma, Z., Xu, S., Jin, S., and Jiang, Y. 2013. Integrated management of wheat stripe rust caused by Puccinia striiformis f. sp. tritici in China. Sci. Agric. Sin. 46:4254-4262.

Chen, X. M. 2005. Epidemiology and control of stripe rust [Puccinia striiformis f. sp. tritici] on wheat. Can. J. Plant Pathol. 27:314-337.

Coakley, S. M., Boyd, W. S., and Line, R. F. 1982. Statistical models for predicting stripe rust on winter wheat in the Pacific Northwest. Phytopathology 72: 1539-1542.

Coakley, S. M., and Line, R. F. 1981. Quantitative relationship between climatic variables and stripe rust epidemics on winter wheat. Phytopathology 71:461467.

Coakley, S. M., Line, R. F., and McDaniel, L. R. 1988. Predicting stripe rust severity on winter wheat using an improved method for analyzing meteorological and rust data. Phytopathology 78:543-550.

Fang, S., Tan, K., Ren, S., Zhang, X., and Zhao, J. 2012. Fields experiments in North China show no decrease in winter wheat yields with night temperature increased by $2.0-2.5^{\circ}$ C. Sci. China Earth Sci. 55:1021-1027.

Grabow, B. S., Shah, D. A., and DeWolf, E. D. 2016. Environmental conditions associated with stripe rust in Kansas winter wheat. Plant Dis. 100:2306-2312.

Li, Z. Q., and Zeng, S. M. 2002. Wheat Rust in China. China Agricultural Press, Beijing.

Liu, X., Wang, X. J., and Han, J. Q. 2017. Status and prospect of winter wheat in Qinghai. China Seed Industry 2:14-17.

Ma, L., Kong, X., Qiao, J., An, F., Hu, X., and Xu, X. 2016. Overwintering of Puccinia striiformis f. sp. tritici on winter wheat at varying altitudes in Gansu and Qinghai provinces. Plant Dis. 100:1138-1145.

Ma, L., Qiao, J., Kong, X., Zou, Y., Xu, X., Chen, X., and Xiaoping, H. 2015. Effect of low temperature and wheat winter-hardiness on survival of Puccinia striiformis f. sp. tritici under controlled conditions. PLoS One 10:e0130691.

Ma, Z. H., Shi, D. S., Jiang, Y. Y., and Zhao, Z. H. 2005. Climate-based regional classification for oversummering of Puccinia striiformis in China with GIS. Acta Phytopathol. Sin. 34:455-462.

Pan, G., Chen, W. Q., Liu, T. G., Gao, L., Cao, S. Q., and Wang, X. M. 2011. Survey of overwintering Puccinia striiformis f. sp. tritici at different altitudes in the areas of Tianshui, Gansu Province. Plant Prot. 37:103-106.

Sharma-Poudyal, D., Chen, X., and Rupp, R. A. 2014. Potential oversummering and overwintering regions for the wheat stripe rust pathogen in the contiguous United States. Int. J. Biometeorol. 58:987-997.

Sharma-Poudyal, D., and Chen, X. M. 2011. Models for predicting potential yield loss of wheat caused by stripe rust in the U.S. Pacific Northwest. Phytopathology 101:544-554.

Sharp, E. L., and Hehn, E. R. 1963. Overwintering of stripe rust in winter wheat in Montana. Phytopathology 53:1239-1240.

Shen, Q. Y., and Wang, K. N. 1962. Research status and future directions on epidemiology of wheat stripe rust in China. Acta Phytophylac. Sin. 1:393-402.

Su, J., Liu, C., Coombes, M., Hu, X., Wang, C., Xu, X., Li, Q., Guo, L., and Chen, W.-H. 2018. Wheat yellow rust monitoring by learning from multispectral UAV aerial imagery. Comput. Electron. Agric. 155:157-166.

$\mathrm{Xu}, \mathrm{X} .-\mathrm{M} ., \mathrm{Ma}, \mathrm{L}$. , and Hu, X. 2019. Overwintering of wheat stripe rust under field conditions in the northwestern regions of China. Plant Dis. 103:638-644.

Yao, Q., Guo, Q. Y., Yan, J. H., Zhang, G., Hou, S. Y., and Chen, W. Q. 2014. Survey on overwintering Puccinia striiformis f. sp. tritici at different altitudes in eastern Qinghai. Acta Phytophylac. Sin. 41:573-578. 